DOI: $10.17516 / 1997-1397-2021-14-2-193-203$

УДК 622.691.4:622.279.72

\title{
Method for Determining the Mass Flow for Pressure Measurements of Gas Hydrates Formation in the Well
}

\author{
Natalya N. Borisova* \\ North-Eastern Federal University named after M. K. Ammosov \\ Yakutsk, Russian Federation \\ Igor I. Rozhin ${ }^{\dagger}$ \\ Institute of Oil and Gas Problems SB RAS \\ Federal Research Center "Yakut Scientific Center SB RAS" \\ Yakutsk, Russian Federation
}

Received 02.09.2020, received in revised form 25.10.2020, accepted 10.01.2021

\begin{abstract}
The work focuses on the inverse problem of determining differential equation coefficients for additional information on the behavior of solution. Furthermore, the algorithm for determining parameters of systems of ordinary differential equations on the basis of stomatal pressure measurements is generalized for the model of hydrate formation when the internal well section of changes with time and also has to be determined during the solution of the general problem. The computational experiment has been conducted for wells of Otradninsky gas condensate deposits of the Republic Sakha (Yakutia), the exploitation of which indicates that the complications are most likely caused by formation of gas hydrates both in the bottom-hole and in the well and its plumes. It has been established that the most important influence on the dynamics of hydrate plugs formation in wells is the gas production mode, its equation of state, reservoir and geocryological conditions. Time dependency of mass flow has been determined, which knowledge will make it possible to control the change of flow area of the entire well and, if necessary, to prevent and remove formation of natural gas hydrates.
\end{abstract}

Keywords: conjugated problems of heat exchange, production and transport of natural gas, natural gas hydrates, mathematical modeling.

Citation: N.N. Borisova, I.I. Rozhin, Method for Determining the Mass Flow for Pressure Measurements of Gas Hydrates Formation in the Well, J. Sib. Fed. Univ. Math. Phys., 2021, 14(2), 193-203.

DOI: 10.17516/1997-1397-2021-14-2-193-203.

When studying physical phenomena or objects by means of empirical methods, there are often circumstances in which no possible direct observation and measurement of any characteristics of object are noted. The experiment may be associated with technical and material difficulties, considered as a dangerous or simply not feasible process. It is almost possible to obtain any additional information about the object for making appropriate conclusions. In such situations for diagnostics of objects (for example, their internal structure) mathematical processing and interpretation of observation are required. These tasks are required to determine the reasons if the consequences obtained are known as a result of the observation. Such kinds of tasks are called the inverse problems [1]. The inverse problem is the problem of determining model parameters based on available observations of model states.

\footnotetext{
*kaf_teplofiz@mail.ru

†i_rozhin@mail.ru https://orcid.org/0000-0002-9998-6425

(C) Siberian Federal University. All rights reserved
} 
The inverse problems are critical in the modeling, control and operation on technologic processes in complex systems. In particular, this applies to oil and gas production processes related to the filtration and flow through pipes of structured multi-component multi-phase liquids having complex rheological properties (oil with paraffin and tarry asphaltene inclusions, oil-water-gas mixtures, drilling solutions of polymers and surface-active substances, etc.). In accordance with the analysis of experimental information raising and solution of the inverse problem allows to select an adequate model, evaluate its parameters and determine if necessary, missing initial and boundary conditions [2].

Solution of practical problems of gas production and transportation is impossible without use of the most modern achievements of mechanics of liquid and gas and applied mathematics. In the monography [3] solutions of the inverse problems for hydraulic models are considered described by the ordinary differential equations. Such models in hydraulics always correspond to the established flow modes. In this case, the characteristic of the process is not time-dependent.

The established modes are convenient for the solution of identification problems. This is due, first, to the fact that it is quite simple to measure time-independent values in practice, and, second, to the fact that the inverse problems are much easier to solve in the case of ordinary differential equations than in the case of partial differential equations. The identifiable parameters must be effectively incorporated into ordinary differential equations or boundary conditions after the non-stationary terms have been discarded. Among the various numerical methods of solving boundary problems, the most effective are the different modifications of the sweep method (for linear problems) and the combination of Newton methods (quasi-linearization) and sweep method. The characteristic feature of these methods is the reduction of the resolution of boundary problems to the solution of Cauchy problems [3].

An analysis of the methods used to calculate the parameters of gas pipelines and wells by M. A. Kanibolotsky showed that they were very approximate character. For direct gas flow calculations, when all design parameters are known by setting boundary conditions, the pressure and temperature distribution can be found [4].

The coefficient of hydraulic resistance and the coefficient of heat exchange are considered the main phenomenological parameters of the mathematical model of the non-isothermal flow of real gas in the well. These values can be found in three ways: 1) through empirical and semiempirical relationships that are based on small, and sometimes misunderstood, experimental data, so that they are not devoid of elements of randomness and limitation; 2) description of the non-isothermal flow of gas in pipes within the theory of boundary layer; 3) identification of the well model using additional information on the behavior of the model on pressure and temperature measurements in the well and wellhead; which will serve as boundary conditions for the definite system [3].

The use of additional measurements to determine the coefficient of hydraulic resistance and the coefficient of heat exchange has been used before [5]. However, to process the results of these measurements, simplified models were chosen that neglected the real properties of gas, non-isothermal flow, etc. It was not feasible to calculate directly on more accurate models with such inaccurate identification. The identification method proposed in the monograph [3] makes it possible to find parameters without simplifying the model chosen in such a way as to ensure the required accuracy of the direct calculations.

The natural gas production process is the most important solution of the inverse problems among the complex systems. Gas hydrates may form at this process.

Gas hydrates are divided into natural and technogenic (artificial). The natural gas hydrates 
may form clusters with a foreseeable industrial significance and may also be scattered. Gas hydrates are currently found in the natural precipitation of the oceans and seas, in the subsoil of the mainland and islands, in the ice of Antarctica and Greenland [4].

Technogenic hydrates are formed in oil and gas production systems: in the bottom-hole, gas and oil wells, plumes and in gas pipelines. In the process of oil and gas production, artificial hydrates are undesirable and methods for preventing and eliminating hydrates have been developed and improved.

The main factors determining the possibility of natural gas hydrates formation under reservoir conditions are: gas composition, reservoir pressure and temperature, the degree of mineralization of pore water. The conditions of hydrate formation are mainly determined experimentally, although these experiments are difficult to perform due to the non-stoichiometry and instability of hydrates. A large number of methods are noted for calculating equilibrium conditions of hydrate formation [4].

In the well gas is intensively cooled by throttling at reduced pressure (isoenthalpic process for gas production and transport [6]) and by means of heat exchange caused by surrounding permafrost rocks. Since many deposits in the northern regions have fairly high reservoir pressures, there is a risk of gas hydrates formation. The formation of hydrates in the bottom-hole results in less productivity and lower capacity in the wells or in their total blockage. The risk of gas hydrates blocking the wells also occurs when they stop due to the low temperature of the surrounding rocks [7].

To describe the formation and deposition of hydrates in the well, a quasi-stationary mathematical model $[4,6-9]$ is applied, in which movement of the real gas in the pipes is described within the tube hydraulics, while the dynamics of hydrate formation presented within the generalized Stefan problem, in which the temperature of the phase transition «gas + water=hydrate» depends on the pressure in the gas flow. Based on the laws of mass and energy conservation for the gas flow, the equations of continuity, motion and energy of gas is reduced to a system of two ordinary differential equations concerning pressure and temperature [10]. This model is closed by some phenomenological ratios corresponding to a level of description of physical phenomena, so that in the equations there are inevitably some constants revealed by additional information on the basis of the chosen model [11] which can be used, for example, the measurements of gas pressure and temperature. In addition to the phenomenological constants, the model includes technological parameters that can also be characterized by these measurements, such as the gas mass flow, noted as a constant in the stationary mode.

This inverse problem of determining differential equation coefficients is considered in some additional information on the behavior of the solution [7], furthermore, the algorithms for determining parameters of the systems of ordinary differential equations on additional measurements are presented in the works $[3,7,12]$, and generalized for the hydrate formation model demonstrated in $[4,6-9]$.

\section{Formulation of the problem}

An essential feature of the model studied is the determination of the time-changing well section area, together with the calculation of gas temperature and pressure distribution from the solution of the Cauchy problem for the equation, describing the variation of the dimensionless area of the well section in the course of time

$$
\frac{d S}{d \tau}=b_{2} \frac{T_{e}-T_{p h}(p)}{1-b_{2} \ln S}-b_{1} \sqrt{S}\left(T_{p h}(p)-T\right)
$$


where $b_{1}=\frac{\alpha_{1} d_{0}}{4 \lambda_{h}}, b_{2}=\frac{\alpha_{2} d_{0}}{4 \lambda_{h}}, \alpha_{1}$ is the coefficient of heat exchange between the gas and the hydrate layer; $\alpha_{2}$ is the coefficient of heat exchange between the hydrate layer and the rock; $d_{0}$ is the well diameter before hydrate formation; $\lambda_{h}$ the coefficient of hydrate heat conductivity; dimensionless time $\tau=\frac{\lambda_{h} T_{c}}{\rho_{h} q_{h} d_{0}^{2}} ; p$ is the gas pressure, $S$ the dimensional cross section, $T$ the gas temperature, $T_{e}$ the temperature of the surrounding rocks, $T_{c}$ is the gas critical temperature; $\rho_{h}$ the density of hydrate; $q_{h}$ the specific heat of the phase transition "gas+water=hydrate"; $t$ is the time; $T_{p h}(p)=a \ln (p)+b$ the is equilibrium temperature of hydrate formation, where the empirical coefficients $a$ and $b$ depend on the gas composition. In the equation (1), all temperature values are assigned to the critical gas temperature $T_{c}$, the coefficient $\alpha_{1}$ depends on the timechanging area of the well section $S$ as follows:

$$
\frac{\alpha_{1} d_{0}}{\lambda_{g}}=0.023 \operatorname{Pr}^{0,43}\left(\frac{M}{d_{0} \eta_{g}}\right)^{0.8}\left(\frac{4}{\pi}\right)^{0.8} \frac{1}{S^{0.9}}
$$

where $\operatorname{Pr}$ is the Prandtl number, $M$ is the gas mass flow, $\eta_{g}$ and $\lambda_{g}$ are the coefficients of gas dynamic viscosity and its heat conductivity

In the equation (1), the coefficient of heat exchange in the well sections is calculated by the formula (2), where the hydrate layer is formed, i.e., where the dimensionless value of the section $S$ is less than 1, and the temperature of the rocks $T_{e}$ is replaced by the temperature of the phase transition $\ll$ gas + water $=$ hydrate» $T_{p h}$.

The algorithm for solving the inverse problem of determining the gas mass flow at variable length and time of the well section according to pressure measurements, which will make it possible to identify signs of hydrates formation in it, varying pressure and temperature distribution over its length.

Following the method described in the work [3], and using the mathematical model proposed in $[7,8]$, we can set the zero approximation $M^{0}$ and compute $p^{0}(x)$ and $T^{0}(x)$, presenting the equations of this model in the form of quasi-stationary equations of tube hydraulics [4, 6-9]:

$$
\begin{gathered}
\frac{d p}{d x}=-\rho g-\frac{\sqrt{\pi} \psi M^{2}}{4 \rho S^{2.5} S_{0}^{2.5}}, \\
\frac{d T}{d x}-\varepsilon \frac{d p}{d x}=\frac{\pi d \alpha}{c_{p} M}\left(T_{e}-T\right)-\frac{g}{c_{p}},
\end{gathered}
$$

where $c_{p}$ is the specific heat capacity of gas at constant pressure, $d_{w}$ is the well diameter, $g$ is the acceleration of gravity, $M=\rho v S S_{0}$ is the mass gas flow, $S_{0}$ is the dimensional section before the formation of hydrates, $x$ is the coordinate along the well axis, $\alpha$ is the total coefficient of heat transfer, $\varepsilon=\frac{R T^{2}}{c_{p} p}\left(\frac{\partial Z}{\partial T}\right)_{p}-$ throttling factor, $\rho$ - gas density; $v-$ gas flow velocity, $\psi-$ hydraulic resistance coefficient, $R$ is the gas constant. The compressibility coefficient of gas in contrast to the work $[4,7]$ instead of the Bertlo equation is determined by the Latonov-Gurevich equation [13], which corresponds appropriately with the reference data [14]:

$$
z=\left(0.17376 \ln \frac{T}{T_{c}}+0.73\right)^{\frac{p}{p_{c}}}+0.1 \frac{p}{p_{c}}
$$

where $p_{c}, T_{c}$ are the critical values of natural gas pressure and temperature, which are determined by the critical value sum of each component per gas content.

To the linearized approximation system $(3-4)$ referring $(s+1)$ : 


$$
\begin{aligned}
& \frac{d p^{s+1}}{d x}=f_{1}^{s}+\left(\frac{\partial f_{1}}{\partial p}\right)^{s}\left(p^{s+1}-p^{s}\right)+\left(\frac{\partial f_{1}}{\partial T}\right)^{s}\left(T^{s+1}-T^{s}\right)+\left(\frac{\partial f_{1}}{\partial M}\right)^{s}\left(M^{s+1}-M^{s}\right), \\
& \frac{d T^{s+1}}{d x}=f_{2}^{s}+\left(\frac{\partial f_{2}}{\partial p}\right)^{s}\left(p^{s+1}-p^{s}\right)+\left(\frac{\partial f_{2}}{\partial T}\right)^{s}\left(T^{s+1}-T^{s}\right)+\left(\frac{\partial f_{2}}{\partial M}\right)^{s}\left(M^{s+1}-M^{s}\right),
\end{aligned}
$$

we can set $p^{s+1}(x)$ and $T^{s+1}(x)$, expressed through the sweeping coefficients $C$ and $D$

$$
\begin{aligned}
& p^{s+1}=C_{1} M^{s+1}+D_{1}, \\
& T^{s+1}=C_{2} M^{s+1}+D_{2} .
\end{aligned}
$$

As the result of these coefficients we obtain the following equations:

$$
\begin{gathered}
\frac{d C_{1}}{d x}=\left(\frac{\partial f_{1}}{\partial p}\right)^{s} C_{1}+\left(\frac{\partial f_{1}}{\partial T}\right)^{s} C_{2}+\left(\frac{\partial f_{1}}{\partial M}\right)^{s}, \\
\frac{d C_{2}}{d x}=\left(\frac{\partial f_{2}}{\partial p}\right)^{s} C_{1}+\left(\frac{\partial f_{2}}{\partial T}\right)^{s} C_{2}+\left(\frac{\partial f_{2}}{\partial M}\right)^{s}, \\
\frac{d D_{1}}{d x}=\left(\frac{\partial f_{1}}{\partial p}\right)^{s}\left(D_{1}-p^{s}\right)+\left(\frac{\partial f_{1}}{\partial T}\right)^{s}\left(D_{2}-T^{s}\right)+f_{1}^{s}-\left(\frac{\partial f_{1}}{\partial M}\right)^{s} M^{s}, \\
\frac{d D_{2}}{d x}=\left(\frac{\partial f_{2}}{\partial p}\right)^{s}\left(D_{1}-p^{s}\right)+\left(\frac{\partial f_{2}}{\partial T}\right)^{s}\left(D_{2}-T^{s}\right)+f_{2}^{s}-\left(\frac{\partial f_{2}}{\partial M}\right)^{s} M^{s},
\end{gathered}
$$

and initial states

$$
C_{1}(0)=C_{2}(0)=0, \quad D_{1}(0)=p_{0}, \quad D_{2}(0)=T_{0} .
$$

After numerical solution of these problems Cauchy, using the exit condition $p(L)=p_{y}$ and the ratio (7), we detect

$$
M^{s+1}=\frac{p_{y}-D_{1}(L)}{C_{1}(L)},
$$

where $L$ is the length of the well, $p_{y}$ is the pressure on the wellhead.

The algorithm for the numerical solution of the conjugate problem of the well heat exchange with frozen rocks can now be described as follows:

1. Set the zero approximation of the flow rate $M^{0}$, which is formed by a simplified model of the isothermal flow of ideal gas without the formation of hydrate $(S=1)$ :

$$
M^{0}=\left(\frac{4}{\sqrt{\pi}} \frac{g S_{0}^{2.5}}{\psi R^{2} T_{0}^{2}}\left(\frac{p_{0}^{2} e^{-\frac{2 g L}{R T_{0}}}-p_{y}^{2}}{1-e^{-\frac{2 g L}{R T_{0}}}}\right)\right)^{\frac{1}{2}} .
$$

2. Compute from equation (15):

$$
p_{y}^{0}(x)=\left(p_{0}^{2} e^{-\frac{2 g L}{R T_{0}}}-\frac{\sqrt{\pi} \psi R^{2} T_{0}^{2}\left(M^{0}\right)^{2}}{4 g S_{0}^{2.5}}\left(1-e^{-\frac{2 g L}{R T_{0}}}\right)\right)^{\frac{1}{2}} .
$$

3. Define the initial values of the sweeping coefficients on the equations (13) by means of them the following solutions (7) and (8) are expressed.

4. Solving the Cauchy problem for the system (9)-(12) by the Runge-Kutta method of the order 4 , find $C_{1}(x)$ and $D_{1}(x)$.

5 . In the equation (14) determine the flow rate $M^{s+1}$.

6. By setting in the ratio (7) to (8), find $p^{s+1}(x)$ and $T^{s+1}(x)$. 
7. Repeat the items 3 to 6 until the necessary precision is achieved. This parameter is determined by nature of the object on which measurements are made, where the accuracy of the measurement equipment (i.e. input data) is of great importance. Calculations have shown that the necessary accuracy of determining the model parameters with an error determined by modern measuring equipment is achieved with 3-8 measurement points. In all cases, the convergence of successive approximations with a relative accuracy of $1 \%$ required 2-4 iterations.

8. From the equation (1), taking the time step, using the Runge-Kutta method, find a new value of the section area. In this case, the $x$-coordinate is included as a parameter in this equation.

9. Determinate the temperature distribution in the rock mass, that is to say, solve the initial-boundary problem for the thermal conductivity equation by the pass-through method with smoothing the breaking coefficients by temperature in the surroundings of the phase transition according to the approach described in the work [8]. Since the smoothed coefficients depend on temperature, the resulting difference problem is nonlinear and its solution is detected by the method of simple iteration using the sweeping algorithms. The algorithm phase is performed only when the task is conjugated.

At each time step, items 3 to 9 are repeated.

To evaluate the accuracy of the finite-difference scheme developed on the basis of the Samarsky-Moiseenko method [15], the results of numerical calculation were compared with the exact self-similar solution of thawing problem an unlimited rock mass at a constant temperature of exposure at the boundary [16]. Based on the dynamics of the phase front movement of thawing rocks, it is found that the speed of the phase front decreases over time due to the low thermal inertia of the thawed zone of rocks. The insignificant difference between the results of calculating the thawing of rocks is explained by the fact that in the exact self-similar solution, in contrast to the numerical solution, the rock is considered unlimited, that is, due to the lack of a heat-insulated boundary, favorable conditions are created. For the numerical solution of this one-dimensional problem, a boundary condition of the 1st kind is assumed for the radius of thermal influence. The results of comparing the exact self-similar and numerical solutions allow us to conclude that the developed finite-difference scheme and computational algorithm are correct.

\section{Results of the computational experiment}

The calculations were carried out at the following parameter values corresponding to the Otradninsky gas condensate deposit of the Sakha Republic (Yakutia) [9]: $\alpha=5.82 \mathrm{~W} /\left(\mathrm{m}^{2} \cdot \mathrm{K}\right)$, $R=438.271 \mathrm{~J} /(\mathrm{kg} \cdot \mathrm{K}), d_{w}=0.146 \mathrm{~m}, \varphi=90^{\circ}, \psi=0.02, \rho_{h}=920 \mathrm{~kg} / \mathrm{m}^{3}, q_{h}=510000 \mathrm{~J} / \mathrm{kg}$, $\lambda_{h}=1.88 \mathrm{~W} /(\mathrm{m} \cdot \mathrm{K}), \lambda_{g}=0.0307 \mathrm{~W} /(\mathrm{m} \cdot \mathrm{K}), c_{p}=2300 \mathrm{~J} /(\mathrm{kg} \cdot \mathrm{K}), \eta_{g}=1.3 \cdot 10^{-5} \mathrm{~Pa} \cdot \mathrm{s}, p_{0}=$ $=188.352 \cdot 10^{5} \mathrm{~Pa}, T_{0}=286.35 \mathrm{~K}, p_{c}=44.679 \cdot 10^{5} \mathrm{~Pa}, T_{c}=195.376 \mathrm{~K}, a=6.635 \mathrm{~K}, b=$ $=182.951 \mathrm{~K}$,

$$
T_{e}= \begin{cases}T_{e 0}-\Gamma x, & 0<x<L-H ; \\ 272.15 K, & L-H<x<L .\end{cases}
$$

$L=2480 \mathrm{~m}, H=680 \mathrm{~m}, T_{e 0}=286.48 \mathrm{~K}, \Gamma=0.0074 \mathrm{~K} / \mathrm{m}$, gas content (об.\%): $\mathrm{CH}_{4}-83.15$, $\mathrm{C}_{2} \mathrm{H}_{6}-4.16, \quad \mathrm{C}_{3} \mathrm{H}_{8}-1.48, \quad \mathrm{iC}_{4} \mathrm{H}_{10}-0.17, \mathrm{nC}_{4} \mathrm{H}_{10}-0.50, \quad \mathrm{iC}_{5} \mathrm{H}_{12}-0.12, \mathrm{nC}_{5} \mathrm{H}_{12}-0.17$, $\mathrm{C}_{6} \mathrm{H}_{14}-0.17, \mathrm{C}_{7} \mathrm{H}_{16+}-0.28, \mathrm{CO}_{2}-0.07, \mathrm{~N}_{2}-9.50, \mathrm{H}_{2}-0.02, \mathrm{He}-0.21$. The pressure at the wellhead ranged from $11 \mathrm{MPa}$ to $14 \mathrm{MPa}$. 
Comparing to experimental data is very difficult and always requires the expenses of facilities and time. Therefore, only theoretical numeral calculations are performed. There are practically no model tests or studies on these processes. In process fact sheets are not considered about hydrate formation on the indicated deposit. During the operation of wells in the Otradninsky deposit, due to the low reservoir temperature, even with small depressions on the formation, intensive hydrate formation occurs in the wellbore and a sharp decrease in gas inflow. For this reason, the bottom-hole zone of wells is pre-treated with methanol. Further operation of gas wells has shown that one of the main causes of complications is the formation of hydrate plugs in the pump and compressor pipes and wellhead equipment. This is understandable, since the wellhead temperature of operating wells is $1^{\circ} \mathrm{C}$ below zero. Therefore, testing the capabilities of mathematical modeling of the Otradninsky deposit development at this stage is reduced to predicting the presence of gas hydrates before the start of gas production and the possibility of their formation in the bottom-hole zone and the wellbore.

To test an algorithm of the numerical solution, a preliminary comparison of the calculation results with the results presented in [7] and carried out in the case of a main gas pipeline was carried out.

The analysis of the calculation results shows that in the Otradninsky deposit the formation of hydrates can be noted in the absence of inhibitors throughout the well, but more intensively this process takes place in its upper part, approximately corresponding to the permafrost capacity. The complete plugging of the wellhead can be observed approximately in $1 \div 2.5$ hours depending on the pressure drop. At the same time, 25-40\% per cent of the well section will be covered on the bottom-hole (Fig. 1 and Fig. 2).The results of the computational experiment showed that the calculation results of the well section coincide for the conjugate and non-conjugate (at a constant temperature of the rocks) problems. This is due to the relatively rapid formation of hydrates,

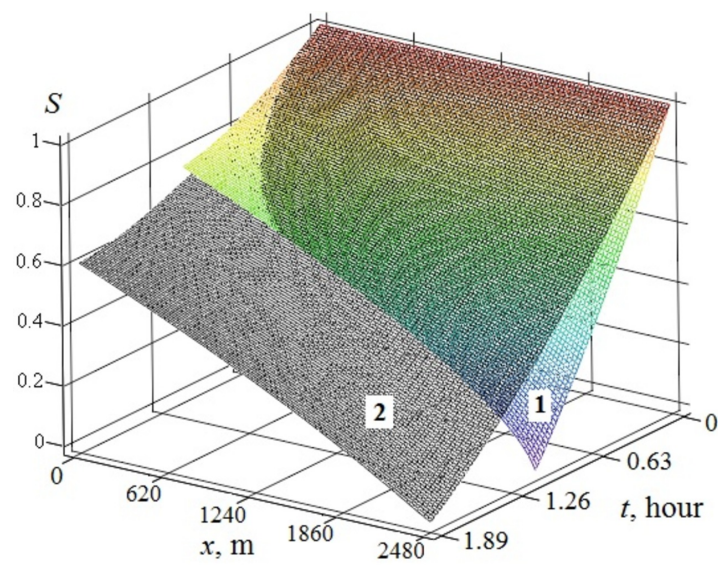

Fig. 1. Dynamics of change in the dimensionless flow area along the well depth at $p_{y}=11 \mathrm{MPa}$ : 1 - real gas, 2 - ideal gas

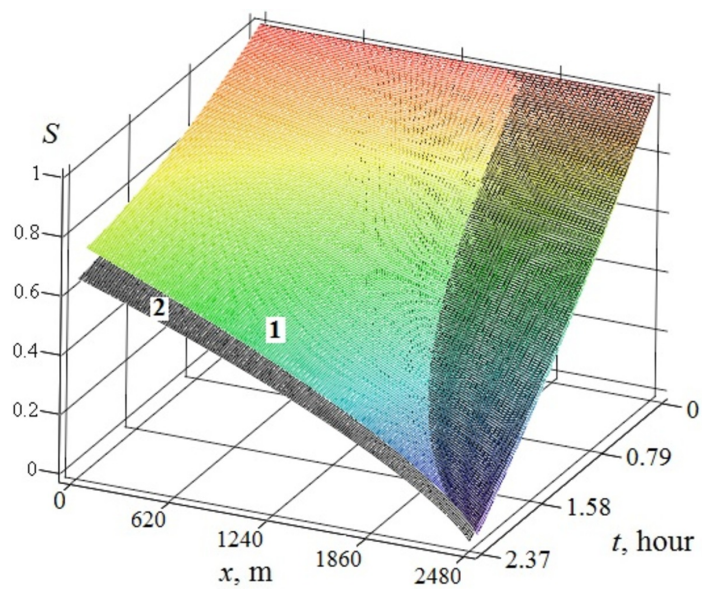

Fig. 2. Dynamics of change in the dimensionless area flow area along the well depth at $p_{y}=14 \mathrm{MPa}: 1$ - real gas, 2 - ideal gas

i.e. the heat exposure time of the rocks is insignificant: at $p_{y}=11 \mathrm{MPa}$ pressure for the real gas is 1.08 hours, for the ideal gas it is 1.89 hours; at $p_{y}=14 \mathrm{MPa}$ for the real gas it is 2.28 hours; for the ideal gas it is 2.37 hours (Fig. 1 and Fig. 2). You can see that the well plugging time for the real gas is shorter, that testifies to the significant role of throttling at relatively 
small pressure ratio. As the depression decreases, the length of the complete hydrate blocking process is almost doubled in the well. In the case of real gas there is less intensive increase of the hydrate layer, than in the case of ideal gas especially at the well bottom . At the same time, the growth dynamics of this layer is more dependent on the pressure in the output section than on the temperature of the rocks [7].

Consequently, in the equal reservoir and geocryological conditions the gas production mode and its state equation have the greatest influence on the dynamics of hydrate cork formation in the wells. As you can see from the Fig. 3, the gas temperature throughout the depth of the well is

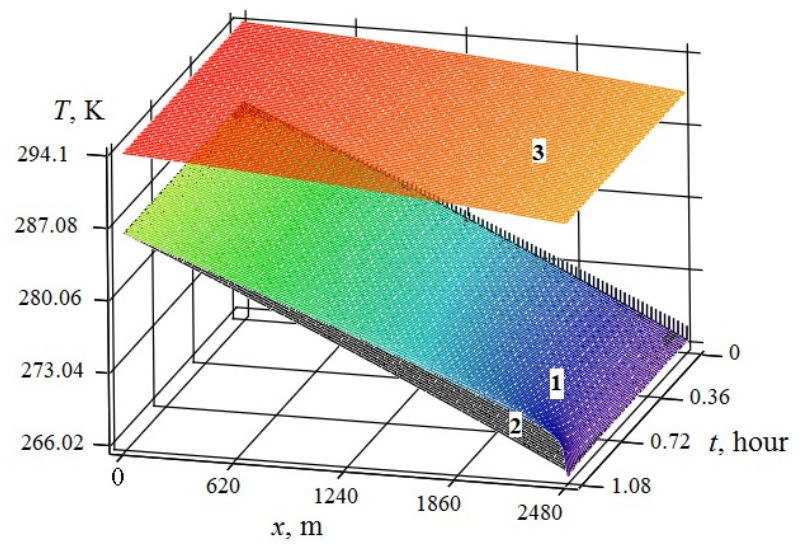

Fig. 3. Gas temperature variation on the well depth and time for Otradninsky deposit at $p_{y}=11 \mathrm{MPa}: 1$ - conjugate statement, 2 - non-conjugate statement, 3 - equilibrium temperature of hydrate formation

lower than the hydrate formation temperature, which proves the rapid plugging of the gas well. The gas temperatures are slightly higher in the conjugate statement than in the unchanging temporal temperature of the surrounding rocks. The case of the temperature change at the well-head pressure $14 \mathrm{MPa}$ is not presented, as the gas temperature values at the conjugate and non-conjugate statement are practically the same.

Fig. 4 and Fig. 5 present the dynamics of changes in the radii of thawing of frozen rocks near the well in the case of real and ideal gas at the wellhead $11 \mathrm{MPa}$ and $14 \mathrm{MPa}$. It can be seen that if in calculating gas is considered to be ideal, the radius of thawing will be about $10 \mathrm{~cm}$ on the permafrost bottom. Due to the shorter time for gas to heat the rocks, the depth of thawing at the wellhead $p_{y}=11 \mathrm{MPa}$ is lower than for $p_{y}=14 \mathrm{MPa}$. This is also confirmed by the temperature variation at the well surface (see Fig. 6 and Fig. 7).

Fig. 8 illustrates the effect of the pressure drop, the gas state and hydrate formation equations on the gas mass flow rate, that is, the capacity of the well. For all variants of calculation no increase of the mass flow is noted at the beginning as it was obtained for the pipeline [7]. This is due to the minor thermal interaction of gas in the well with the surrounding rocks. For gas in the presence of hydrate formation inhibitor, the mass flow rate remains almost constant and, while in the case of hydrates formation it decreases to zero in relatively short time. The rate of decline depends on the gas state equation (compare pairs of lines 3 and 7, 4 and 8). At the same time, it depends on the pressure difference (compare the pairs of lines for the real gas 1,2 and 3,4 , for the ideal gas 5, 6 and 7,8), although this effect can also be explained by the fact that a higher rate of the pressure drop corresponds to the increase in the initial mass flow. 


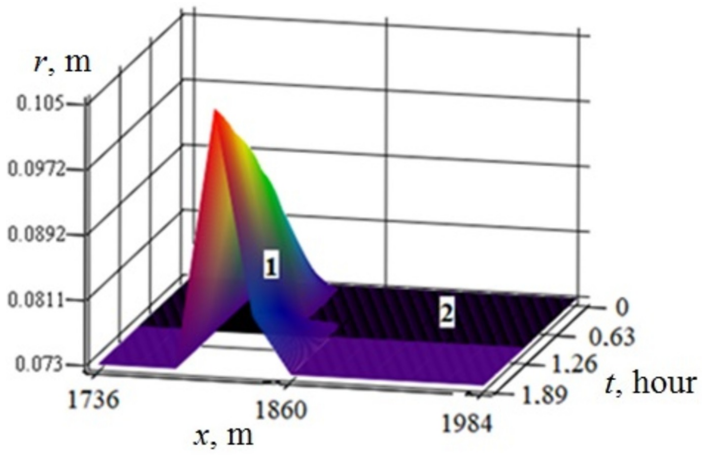

Fig. 4. Variation of the radius at thawing frozen rocks around the well in its depth and time if $p_{y}=11 \mathrm{MPa}: 1$ - ideal gas; 2 - real gas

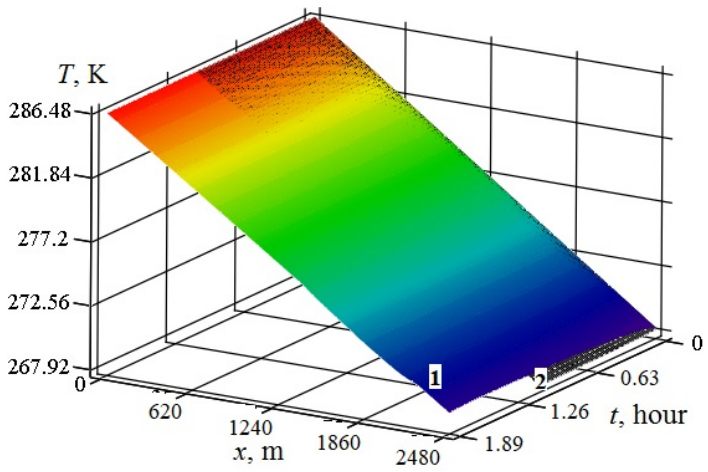

Fig. 6. Variation of temperature on the well surface in its depth and time at $p_{y}=11 \mathrm{MPa}$ 1 - real gas, 2 - ideal gas

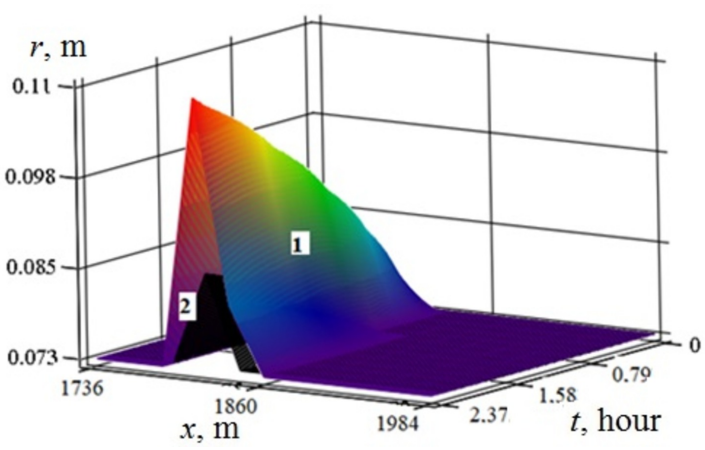

Fig. 5. Variation of the radius at thawing frozen rocks around the well in its depth and time if $p_{y}=14 \mathrm{MPa}: 1$ - ideal gas; 2 - real gas

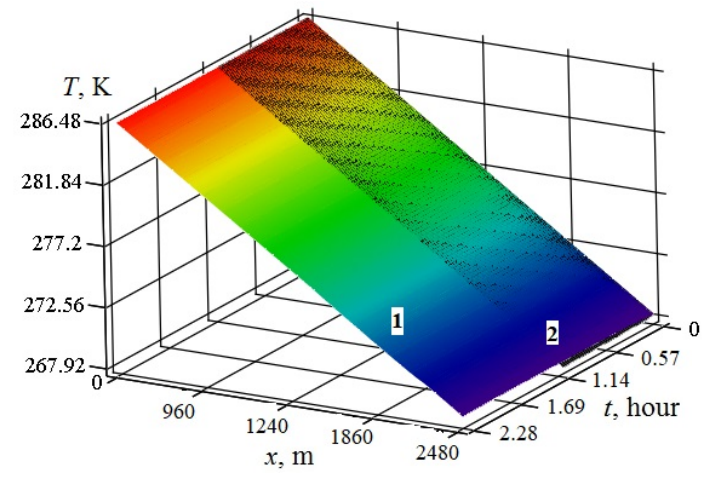

Fig. 7. Variation of temperature on the well surface in its depth and time at: $1-p_{y}=14 \mathrm{MPa}$, $2-p_{y}=11 \mathrm{MPa}$

For lower depression, the initial flow rate for the real gas is lower than for the ideal gas (see curves 1 and 5), and for larger depression it is higher (see curves 2 and 6). But as this initial flow increases, the length of the complete plugging of the wellhead area by hydrates is reduced (see curves 4 and 8). It can be seen that due to throttling in the case of real gas this time is less than in the case of ideal gas.

\section{Conclusion}

Variations in pressure and temperature distribution over the length of the well are the main signs of hydrate formation, the inventive generalized algorithm for solving the inverse problem of determining a mass gas flow at a well cross-section which is variable in time according to the wellhead pressure measurements is disclosed. Knowing the dynamics of changes in the mass flow rate over time, it is possible to control the change in the flow section throughout the well and, if necessary, measures should be taken to prevent and remove natural gas hydrates. 


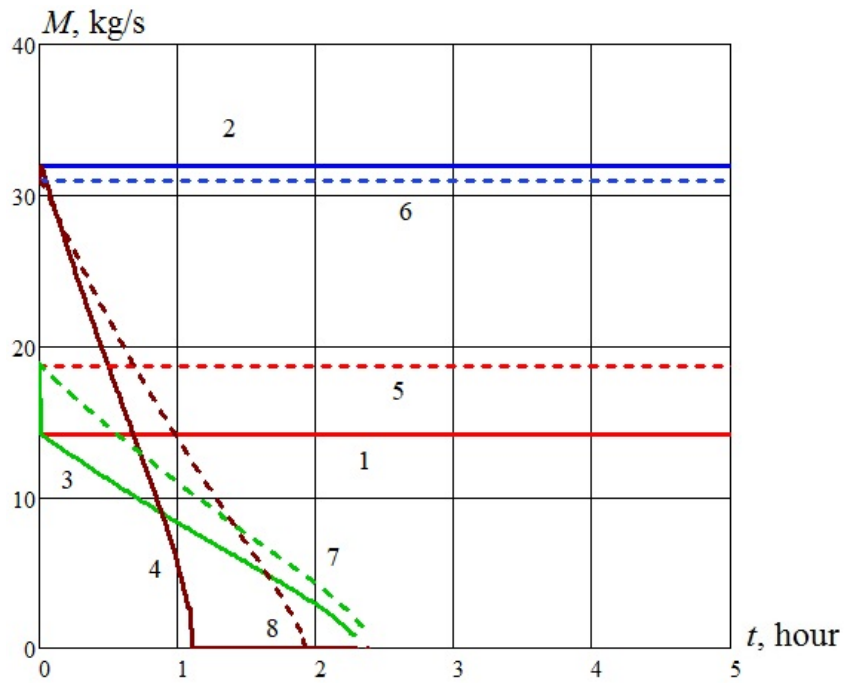

Fig. 8. Mass flow rate dynamics: $1-4$ for real gas (solid lines); $5-8$ for ideal gas (dotted lines); $1,3,5$ and 7 for $p_{y}=14 \mathrm{MPa} ; 2,4,6$ and 8 for $p_{y}=11 \mathrm{MPa} ; 1,2,5$ and 6 - a hydrate free mode; $3,4,7$ and 8 - a hydrate mode

\section{References}

[1] A.I.Korotkiy, Yu.V.Starodubtsev, Modeling of direct and inverse boundary problems for stationary heat and mass transfer models: monography, Ekaterinburg, Ural federal university, EBS ASV, 2015 (in Russian).

[2] A.H.Mirzadzhanzade, M.M.Hasanov, R.N.Bahtizin, Modeling of oil and gas production processes. Nonlinearity, non-equilibrium, uncertainty, Moscow-Izhevsk, Institute of computer researches, 2004 (in Russian).

[3] E.A.Bondarev, A.F.Voevodin, V.S.Nikiforovskaya, Methods of identification of hydraulics mathematical models, Yakutsk, Publishing house NEFU, 2014 (in Russian).

[4] E.A.Bondarev, A.F.Voevodin, Solution of problems of trumpet hydraulics in systems of natural gas production and transport, Novosibirsk, Publishing house of the Siberian Branch of the Russian Academy of Science, 2017 (in Russian).

[5] I.A.Charny, Basis of gas dynamics, Moscow, Gostoptechizdat, 1961 (in Russian).

[6] E.A.Bondarev, V.I.Vasilev, A.F.Voevodin, N.N.Pavlov, A.P.Shadrina, Thermohydrodynamics of gas production and transport system, Novosibirsk, Nauka, Sib. Branch, 1988 (in Russian).

[7] E.A.Bondarev, I.I.Rozhin, K.K.Argunova, A new algorithm of mass flow rate determination in gas production and transport systems via pressure measurement, J. of Applied Mechanics and Technical Physics, 58(2017), no. 5, 853-861. DOI: 10.1134/S002189441705011X

[8] E.A.Bondarev, I.I.Rozhin, K.K.Argunova, Modeling of hydrate formation in gas wells at their thermal interaction with rocks, J. of Engineering Physics and Thermophysics, 87(2014), no. 4, 900-907. DOI: 10.1007/s10891-014-1087-0 
[9] E.A.Bondarev, I.I.Rozhin, K.K.Argunova, Features of mathematical modeling of natural gas production and transport systems in the Russia's arctic zone, J. of Mining Institute, 228(2017), 705-716.

[10] O.F.Vasilev, E.A.Bondarev, A.F.Voevodin, M.A.Kanibolotskiy, Non-isothermal gas current in pipes, Novosibirsk, Nauka, 1978 (in Russian).

[11] I.I.Blehman, A.D.Myshkis, J.G.Panovko, Applied mathematics. Subject, logic, sensitive approaches, Kiev, Naukova Dumka, 1976 (in Russian).

[12] E.A.Bondarev, A.F.Voevodin, M.A.Kanibolotsky, E.A.Metljaeva, Inverse problems of stationary non-isothermal gas current in pipes, Bulletin of the USSR Academy of Sciences. Energy and transport, (1977), no. 1, 143-145 (in Russian).

[13] V.V.Latonov, G.R.Gurevich, Calculation of compressibility factor of natural gases, Gas industry, (1969), no. 2, 7-9 (in Russian).

[14] K.K.Argunova, E.A.Bondarev, I.I.Rozhin, Properties of real gas and their analytical representation, Gas chemistry, 16(2010), no. 6, 52-54 (in Russian).

[15] A.A.Samarsky, B.D.Moiseenko, An economic continuous calculation scheme for the Stefan multidimensional problems, J. Computational Mathematics and Mathematical Physics, 5(1965), no. 5, 816-827 (in Russian).

[16] H.S.Carslow, J.C.Jaeger, Heat conduction of solids, Moscow, Nauka, 1964 (in Russian).

\title{
Метод определения массового расхода по замерам давления при образовании газовых гидратов в скважине
}

\author{
Н.Н. Борисова \\ Северо-Восточный федеральный университет им. М. К. Аммосова, \\ Якутск, Российская Федерация \\ И.И. Рожин \\ Институт проблем нефти и газа СО РАН \\ Федеральный исследовательский центр «Якутский научный центр СО РАН»
}

Якутск, Российская Федерация

\begin{abstract}
Аннотация. Работа посвящена обратной задаче определения коэффициентов дифференциальных уравнений по дополнительной информации о поведении решения. При этом алгоритм определения параметров систем обыкновенных дифференциальных уравнений по замерам устьевого давления обобщается для модели гидратообразования, когда внутреннее сечение скважины изменяется во времени и также подлежит определению в ходе решения общей задачи. Вычислительный эксперимент проведен для скважин Отраднинского газоконденсатного месторождения Республики Саха (Якутия), эксплуатация которых свидетельствует о том, что наиболее вероятной причиной осложнений является образование газовых гидратов как в призабойной зоне, так и в стволе скважин и их шлейфах. Установлено, что наибольшее влияние на динамику образования гидратных пробок в скважинах оказывают режим отбора газа, его уравнение состояния, пластовые и геокриологические условия. Определена зависимость массового расхода по времени, знание которой позволит контролировать изменение проходного сечения по всей скважине и в случае необходимости проводить мероприятия по предотвращению образования и удалению гидратов природного газа.
\end{abstract}

Ключевые слова: сопряженные задачи теплообмена, добыча и транспорт природного газа, гидраты природного газа, математическое моделирование. 